\title{
Standardization of Ionizing Radiation Exposure Terms and Definitions Based on Sohrabi Universal Radiation Protection System Hypothesis
}

\author{
Mehdi Sohrabi* \\ Faculty of Energy Engineering and Physics, Amirkabir University of Technology, Tehran, Iran
}

*Corresponding author: Mehdi Sohrabi, Faculty of Energy Engineering and Physics, Amirkabir University of Technology, Tehran, Iran, E-mail: dr_msohrabi@yahoo.com

Received: 21 Oct, 2019 | Accepted: 08 Nov, 2019 | Published: 15 Nov, 2019

Citation: Sohrabi M (2019) Standardization of Ionizing Radiation Exposure Terms and Definitions Based on Sohrabi Universal Radiation Protection System Hypothesis. J Epidemiol Public Health Rev 4(3): dx.doi.org/10.16966/2471-8211.177

Copyright: (C) 2019 Sohrabi M. This is an open-access article distributed under the terms of the Creative Commons Attribution License, which permits unrestricted use, distribution, and reproduction in any medium, provided the original author and source are credited.

\section{Introduction}

Radiation protection of workers, patients, public and the environment has been continuously evolved over the past 100 years in order to better design, formulate and regularize a system of radiation protection to be implemented worldwide. In this endeavor, some international organizations and committees such as the United Nations Scientific Committee on the Effects of Atomic Radiation (UNSCEAR), International Commission on Radiological Protection (ICRP), International Atomic Energy Agency (IAEA), World Health Organization and International Labor Organization have been highly instrumental such that at present the majority of countries have at least some basic radiation protection regulatory infrastructures at different stages of development. In particular the ICRP, based on the risk estimates provided by the UNSCEAR [1], has made recommendations and guidelines with provision of terms and definitions of ionizing radiation exposures [2]. The ICRP recommendations are highly respected worldwide in order to regularize radiation practices in each country, as I have personally applied it as the Director General of the National Radiation Protection Department in Iran for establishing a National Regulatory Authority. In particular, the IAEA has been highly instrumental in issuing the International Basic Safety Standards on Radiation Protection and Safety of Radiation Sources based on the ICRP recommendations and implementation of the requirements of the standards in its over 140 Member States through which this author also has had a share as an IAEA international expert and in particular as technical staff for near 10 years at the IAEA Headquarters in Vienna [3]. This author having a share in radiation protection research, development and services worldwide with critical thoughts through half a century, has recently hypothesized a novel Universal Radiation Protection System (URPS) with a number of novel concepts, terms, definitions and methodologies in order to address the many deficiencies existing in the current radiological protection philosophy, concept and methodologies worldwide as are discussed in this paper [2,4-10].

The current ICRP radiation protection philosophy is based on risk estimation by applying the linear no-threshold (LNT) model with emphasis that at low doses/dose rates, the excess risk is proportional to the dose as extrapolated from higher doses [2]. In brief, the LNT model states that any level of radiation dose, no matter how small, has a certain degree of health risks with any bio-positive or bio-negative effects occurring above the means global natural background (NBG) radiation dose of $\sim 2.4 \mathrm{mSv} . \mathrm{y}^{-1}[1]$. However, the LNT model has been challenged to be replaced by a hormesis model which states that low doses of ionizing radiation above the NBG radiation exposure are beneficial and stimulate the activation of repair mechanisms that protect against diseases such as cancer $[11,12]$. In particular, the ICRP philosophy currently applied almost worldwide does not respond to the actual doses an individual, either a member of public or a worker being also a member of public, receives from different NBG and manmade sources $[2,4,5]$. For example, workers and members of the public living in different parts of the world receive significant unfractionated national mean NBG doses annually with values which are different from one country to another or even from a city to another, as have been considered trivial and ignored so far in integrating all doses even for radiation workers. The epidemiology risk estimation and in particular the system of dose limitation has ignored and not included non-occupational exposures such as NBG and medical exposures in dose limitation of radiation workers $[4,5]$.

The URPS philosophy, concept and methodologies have been well presented by this author as keynote talks at international conferences and documented in the open literature [4-10]. Briefly speaking, the Sohrabi URPS hypothesizes having equal human health-effect risks of an individual per unit radiation dose, either from NBG or man-made sources [4,5]; applies a "Standardized Integrated Dose System" (SIDS) for integrating all doses an individual receives from different sources of ionizing radiation with emphasis on national NBG doses [8]; proposes a "URPS model" which bridges the LNT and hormesis models [5,7]; introduces and formulates for the first time in radiological protection radiation fractionation weighting factors $\left(\mathrm{W}_{\mathrm{F}}\right)$ in order to modify unrealistic exposures of an individual [9]; considers a worker as a member of the public $[4,5]$; proposes a 
"cause-effect conservation principle" in particular for epidemiology risk estimation [4,10]; suggests an example dose limit of $100 \mathrm{mSv} \cdot \mathrm{y}^{-1}$ for workers by simply applying work-hours fractionation [5,7], which has been supported by Moghissi and co-workers from the Institute for Regulatory Science and Georgetown School of Medicine (USA) [13].

In a very recent article, Abelquist states that "While radiation research in radiation biology and epidemiology are needed to better understand low-dose health effects below $100 \mathrm{mSv}$, in the meantime we should apply what we know-i.e., that radiation protection should not include trying to protect people from radiation doses that are consistent with variations in background radiation" [14]. In particular, the very recent position statement of the Health Physics Society (USA) has claimed that below levels of about $100 \mathrm{mSv}$ above background from all sources combined, the observed radiation effects in people are not statistically different from zero [15]. Accordingly, it seems that $100 \mathrm{mSv}$ is being debated to be the dose limit of workers in the $21^{\text {st }}$ century which is the same as what has been proposed by the Sohrabi URPS hypothesis to reconcile the LNT and hormesis models which has applied time fractionation concept [5,7]. It is also interesting to note that the concept of NBG radiation is being now bolded even by the Health Physics Society in which I have been a member for 50 years $[4,5,13,14,15]$.

Having said the above and in order to meet the URPS hypothesis requirements, some ICRP terms and definitions as well as some new URPS terms and definitions which have been recently developed by this author are provided and compared as follow $[2,4,5]$.

\section{The ICRP has hypothesized 3 fundamental principles of} radiation protection including [2]

a. Justification: Any decision that alters a radiation exposure situation and should do more good than harm.

b. Optimization of protection: Doses should be kept as low as reasonably achievable (ALARA), taking into account economic and societal factors, and

c. Dose limitation: The total dose to any individual should not exceed the appropriate limits from regulated sources in planned exposure situations, other than medical exposure of patients.

\section{The ICRP has also defined 3 exposure situations [2]}

a. Existing exposure situation: A situation that already exists when a decision on control has to be taken.

b. Planned exposure situation: Where radiological protection can be planned in advance, and exposures can be reasonably predicted, and

c. Emergency exposure situation: An unexpected situation that may require urgent protective actions.

The ICRP has also defined 3 types of exposures [2]

a. Occupational exposure: Exposure of workers incurred as a result of their work.

b. Medical exposure: Exposure of patients as part of their diagnosis or treatment, volunteers helping in the support and comfort of patients, and volunteers in biomedical research, and

c. Public exposure: Exposure of members of the public other than occupational and medical exposures, and not including the normal local NBG radiation.

The URPS hypothesis defines a "radiation worker as a member of public with non-occupational exposure commitment plus occupational exposure from work" [3], while ICRP considers worker's exposure only from radiation work occupationally [2]. By applying the SIDS concept, all doses a worker receives either from occupational or non-occupational exposures are integrated in order to standardize risk limit of workers no matter where they live or work in the world. In this regard, some URPS-based source-related exposure terms and definitions on occupational, medical and environmental exposures as well as on exposures of individuals such as workers, public and patients have been newly defined and introduced below [5]. These exposure terms and definitions are intended to conserve their consistency with the URPS philosophy, concepts and methodologies as follow:

\section{Source-related Exposure Types}

\section{a. Environmental exposure}

Exposures from environmental radiation sources and indoors and outdoors due to NBG and man-made sources; this includes mainly exposures from existing and planned exposure situations; the emergency exposure situations can be dealt with under separate terms.

\section{b. Occupational exposure}

Exposures of a worker incurred at work from radiation sources and practices occupationally, and

\section{c. Medical exposure}

Exposures of a patient from diagnostic and/or therapeutic procedures and examinations.

\section{Individual-related Exposure Types}

\section{a. Worker exposure}

Total exposures of a worker from occupational exposure plus nonoccupational public exposure as a member of public by applying radiation protection fractionation weighting factors $\mathrm{W}_{\mathrm{F}}$.

\section{b. Patient exposure}

Exposure of a patient in diagnostic procedures as common exposures of public, not including any therapeutic doses. Exposure of volunteers or helpers in diagnostic procedures, as is included in the ICRP medical exposure definition, can be considered only as public exposure according to the URPS hypothesis, and

\section{c. Public exposure}

Exposure of a member of public from non-occupational exposures such as existing and planned exposure situations as well as patient exposure; The emergency exposure situations can be dealt with as separate exposures on case by case basis.

The URPS has good harmony with the ICRP fundamental principles of radiation protection in terms of justification and optimization, but defines the dose limit differently based on the URPS philosophy and concepts. A new definition of "dose limit" as regards the URPS hypothesis can be tentatively considered as "An annual limit set on ionizing radiation doses an individual receives from non-occupational and/or occupational exposures including also patient exposure respectively for a worker and a member of public".

The above terms and definitions in particular on dose limit are tentative and under further development as the URPS hypothesis is continuously in progress to be further advanced. These terms and definitions are essential towards proper implementation of the URPS hypothesis which is different from those of the ICRP, as given above. However, the URPS philosophy, concepts and methodologies as well as the terms and definitions introduced above are open to constructive 
feedbacks and recommendations from national and international organizations as well as researchers in the field in order to globally accept and apply them for the protection of workers, patients, public and the environment in the $21^{\text {st }}$ century.

\section{References}

1. United Nations (2000) Sources and Effects of Ionizing Radiation: Exposures from Natural Radiation Sources. New York, US.

2. Valentin J (2007) The 2007 Recommendations of the International Commission on Radiological Protection. Ann ICRP.

3. International Atomic Energy Agency (2014) Radiation Protection and Safety of Radiation Sources: International Basic Safety Standard. IAEA Safety Standards, Austria.

4. Sohrabi M (2015) A universal radiation protection system based on individual standardised integrated doses. Radiat Prot Dosimetry 164: 459-466

5. Sohrabi M (2019) Universal Radiation Protection System (URPS); A Natural Global Standardised Trend for Human Exposure Control in $21^{\text {st }}$ Century. Radiat Prot Dosimetry 184: 277-284.

6. Sohrabi M (2015) On Dose Reconstruction for the Million Worker Study: Status and Guidelines. Health Phys 109: 327-329.

7. American Nuclear Society (2018) Bridging the LNT and Hormesis Radiation Protection Models. Nuclear News.
8. Sohrabi M (2016) A Standardized Individual Dose System for Epidemiology of Public and Workers by "Universal Radiation Protection System Hypothesis." J Epidemiol Public Health Rev 1: 1-2.

9. Sohrabi M (2017) Dose Fractionation Concept in Radiation Protection to Standardize Risk/Dose Limits and Epidemiology Studies. J Epidemiol Public Health Rev 2.

10. Sohrabi M (2017) Conservation of "Cause-effect" by using Integrated Individual Radiation Doses towards Standardization of Epidemiology Health Risk Estimates of Nuclear/Radiation Workers. J Nucl Ene Sci Power Generat Technol 6: 1-3.

11. Sanders CL (2017) Radiobiology and Radiation Hormesis: New Evidence and its Implications for Medicine and Society. Springer Nature, Switzerland.

12. Cuttler JM, Hannum WH (2017) Current Radiation Protection Limits: An Urgent Need for Change. ANS, Nuclear News 60: 34-38.

13. Moghissi AA, Calderone RA, Estupigan C, Koch R, Manfredi $K$, et al. (2018) Requirements for Transparency and Communicability of Regulatory Science. Dose Response 16: 1559325818813056.

14. Abelquist EW (2019) To Mitigate the LNT Model's Unintended Consequences-A Proposed Stopping Point for As Low As Reasonably Achievable. Health Phys 117: 592-597.

15. Health Physics Society (2019) Radiation risk in perspective: Position statement of the Health Physics Society. PSO10-4. 